\title{
Overexpression of carbonyl reductase 1 inhibits malignant behaviors and epithelial mesenchymal transition by suppressing TGF- $\beta$ signaling in uterine leiomyosarcoma cells
}

\author{
TAKUYA KAJIMURA, SHUN SATO, AKIHIRO MURAKAMI, MAKI HAYASHI-OKADA, \\ KENGO NAKASHIMA, KOTARO SUEOKA and NORIHIRO SUGINO \\ Department of Obstetrics and Gynecology, Yamaguchi University Graduate School of Medicine, \\ Ube, Yamaguchi 755-8505, Japan
}

Received November 27, 2018; Accepted May 22, 2019

DOI: $10.3892 /$ ol.2019.10429

\begin{abstract}
Carbonyl reductase 1 (CBR1) has been reported to be involved in cancer progression. Recently, we found that CBR1 overexpression inhibited malignant behaviors and the epithelial mesenchymal transition (EMT) in uterine cervical cancer. It remained unclear whether this was also the case in uterine leiomyosarcoma (uLMS), which is derived from mesenchymal cells and is a much more malignant gynecological tumor. A number of previous studies suggested that malignant behaviors are associated with EMT, even in mesenchymal malignant tumors. In the present study, we investigated whether CBR1 inhibits malignant behaviors and EMT in uLMS. We established clones of uLMS cells (SKN cells) and uterine sarcoma cells (MES-SA cells) that overexpressed CBR1. Cell proliferative, migratory and invasive activities were suppressed by CBR1 overexpression, accompanied by increases in the expressions of epithelial markers (E-cadherin and cytokeratin) and decreases in the expressions of mesenchymal markers (N-cadherin and fibronectin), suggesting that CBR1 overexpression inhibits malignant behaviors and EMT in uLMS cells. In addition, transforming growth factor- $\beta$ (TGF- $\beta$ ) production and the subsequent signaling and phosphorylation of Smad were suppressed in the clones. To investigate the association between TGF- $\beta$ and EMT, SKN cells were treated with TGF- $\beta$ or a TGF- $\beta$ receptor blocker (SB431542). EMT was promoted by TGF- $\beta$ and inhibited by SB431542. In conclusion, this is the first study, to the best of the authors' knowledge, showing that CBR1 overexpression inhibits malignant behaviors and EMT in uLMS cells. The present study provided novel insight demonstrating that the suppressive effect of CBR1 is mediated through TGF- $\beta$ signaling.
\end{abstract}

Correspondence to: Professor Norihiro Sugino, Department of Obstetrics and Gynecology, Yamaguchi University Graduate School of Medicine, 1-1-1 Minamikogushi, Ube, Yamaguchi 755-8505, Japan E-mail: sugino@yamaguchi-u.ac.jp

Key words: carbonyl reductase 1, uterine leiomyosarcoma, epithelial mesenchymal transition, transforming growth factor- $\beta$

\section{Introduction}

Uterine leiomyosarcomas (uLMS) are relatively rare but highly malignant gynecological mesenchymal tumors. uLMS are derived from smooth muscle of the myometrium, and are the most common subtype of uterine sarcomas (1). Although uLMS account for only about $1 \%$ of uterine malignancies, they account for about $70 \%$ of all uterine cancer deaths (2). Hysterectomy is the standard treatment for uLMS. However, even for uLMS patients that received complete surgical treatments, the risk of recurrence after surgical treatments was high (50-71\%) because of the aggressive nature of uLMS (3-9). The poor prognosis is reflected by 5 -year disease-specific survival rates of less than $30 \%$ (10-12). Therefore, there is a need for an effective therapeutic strategy for uLMS.

Carbonyl reductase 1 (CBR1) is a nicotinamide adenine dinucleotide phosphate-dependent, mostly monomeric, cytosolic enzyme with a broad substrate specifically for carbonyl compounds $(13,14)$. CBR1 is present in a variety of organs including liver, kidney, breast, ovary, and vascular endothelial cells, and its primary function is considered to control fatty acid metabolism (15). Interestingly, CBR1 has been reported to regulate malignant behaviors of cancer cells: Decreasing the expression of CBR1 induced cell proliferation and tumorigenesis in vitro and in vivo experiments accompanied by a decreased expression of E-cadherin, and activated matrix metalloproteinases (MMPs) in ovarian, uterine cervical, or uterine endometrial cancers (16-21). This suggests that the decreased expression of CBR1 promotes tumor growth and invasion activities. Furthermore, low-expression of CBR1 is closely associated with lymph node metastasis and a poor prognosis in ovarian, uterine cervical, or endometrial cancers $(17,18,20)$. In contrast, increasing the expression of CBR1 repressed the activities of cell proliferation and invasion, and tumorigenesis in ovarian, uterine cervical, and endometrial cancers (17-20,22). Additionally, CBR1 overexpression increased E-cadherin expression and decreased $\mathrm{N}$-cadherin expression, indicating that CBR1 expression inhibits the epithelial mesenchymal transition (EMT) $(17,18)$.

EMT is a well-known phenomenon that is associated with the progression of malignant behaviors in epithelial tumors $(23,24)$. 
In the EMT process, cell-to-cell adhesion becomes weak with the decreased expression of E-cadherin, and invasive and metastatic activities are promoted (23-26). Although EMT has been studied in epithelial malignant tumors (cancers), it is of interest to note that EMT is involved in malignant behaviors even in mesenchymal malignant tumors. Several reports have indicated the potential existence of EMT-related processes in sarcomas, suggesting that sarcomas can undergo phenotypic changes reminiscent of EMT (27-32). EMT leads to a gain in mesenchymal activities and promotes malignant behaviors of mesenchymal tumors $(27,30,32,33)$, which may be associated with aggressive clinical behaviors. Therefore, it is important to examine the role of EMT in uLMS as well as in cancers.

RegardingthemechanismofEMT,transforming growthfactor (TGF)- $\beta$, which has roles in cell proliferation, differentiation, and tumorigenesis, has been reported to be closely associated with EMT in many epithelial and mesenchymal tumors $(34,35)$. We previously analyzed pathways that are regulated by CBR1 in a uterine cervical cancer cell line overexpressing CBR1 (21). Of 15 pathways that were analyzed, the TGF- $\beta$ signaling pathway was found to be the most important. This suggests that TGF- $\beta$ signaling is closely associated with EMT, which is regulated by CBR1.

We previously showed that CBR 1 inhibited malignant behaviors by suppressing EMT in uterine cervical squamous cell carcinomas (21). It remained unclear whether this also was the case in uLMS. Therefore, we investigated whether an increase in CBR1 expression inhibits malignant behaviors and EMT through TGF- $\beta$ signaling in uLMS.

\section{Materials and methods}

Cell culture. SKN, which is a human uLMS cell line, and MES-SA, which is human uterine sarcoma cell line, were used in this study. SKN was purchased from Health Science Research Resources Bank (HSRRB, Osaka, Japan), and MES-SA was purchased from American type culture collection (ATCC, Virginia, USA). SKN cells were cultured in Ham's F 12 (Sigma-Aldrich Japan K.K., Tokyo, Japan), and MES-SA cells were cultured in McCoy's 5a medium (ATCC). Both media were supplemented with $10 \%$ heat-incubated fetal bovine serum (FBS). The cells were seeded at a density of $5 \times 10^{4}$ cells/well in a six-well plate, and incubated at $37^{\circ} \mathrm{C}$ in a humidified $5 \% \mathrm{CO}_{2}$ incubator for 5 days. The cells were trypsinized and counted by a cell counter (Vi-CELL XR; Beckman Coulter, Tokyo, Japan) at each time point, as reported previously (36).

For TGF- $\beta$ treatment, cells were cultured in Ham's F12 and McCoy's 5a medium supplemented with 10\% FBS containing 100 or 500 pg/ml TGF- $\beta 1$ (Sigma-Aldrich Japan K.K.) for $24 \mathrm{~h}$. In order to block TGF- $\beta$ signaling, SB431542 (WAKO, Tokyo, Japan), which is a TGF- $\beta$ type I receptor-selective blocker, was dissolved at a concentration of $10 \mu \mathrm{M}$ in dimethylsulfoxide (DMSO). Cells were seeded at a density of $5 \times 10^{4}$ cells/well in a six-well plate and cultured for $24 \mathrm{~h}$ and then cultured with new medium supplemented with $10 \mu \mathrm{M}$ SB431542 for more $48 \mathrm{~h}$.

Gene transfection. To analyze the function of CBR1, stable clones were established in which CBR1 expression was increased. The construct of CBR1 was transfected into SKN and MES-SA by the lipofection method as previously reported $(37,38)$. To improve the efficacy of transfection, we used the pEF1a-IRES-AcGFP vector (Clontech Laboratories, Inc., Mountain View, CA, USA) that encodes human CBR1, green fluorescent protein (GFP) and a neomycin resistance gene. Transfected cells were cultured in Ham's F12 and McCoy's 5a medium for $24 \mathrm{~h}$, and then in medium supplemented with $300 \mu \mathrm{g} / \mathrm{ml}$ neomycin for one month. The overexpression of CBR1 was confirmed by Western blot analysis. A clone transfected with the empty vector was used as a control. In the preliminary experiments, the reagent that was used for transfection did not influence cell mobility or CBR1 expression.

In vitro migration and invasion assays. Cell migration and invasion assays were assayed with a BioCoat Matrigel Invasion Chamber (cat. no. 354480; Corning Life Sciences Inc., Tewksbury, MA, USA) according to the manufacturer's protocol as previously reported (17). This kit is used to measure how well cells can migrate from the upper side of a membrane to the lower side in a 12-well transwell system. Cells were trypsinized, and $5 \times 10^{4}$ cells in serum-free medium were seeded into collagen-coated and uncoated (control) upper insert chambers of the transwell system. The lower chamber was filled with $750 \mu \mathrm{l}$ medium containing $10 \% \mathrm{FBS}$ as a chemo-attractant. After incubation for $20 \mathrm{~h}$, the upper surfaces of the membranes were wiped with cotton swabs to completely remove the cells. The membranes were fixed and stained with Diff-Quick (cat. no. 24606-500; Sysmex, Kobe, Japan). The cells on the lower surfaces of the membranes were counted at 200x magnification in five randomized field views, and the mean was calculated. Migration activities were evaluated by the numbers of cells that migrated to the control chamber. Invasion activities were expressed as the number of cells in the coated chamber divided by the number of cells that migrated to the uncoated chamber. Each experiment was performed in triplicate, and the mean percentage was obtained from three independent experiments. In the experiments with MES-SA cells, we could not see the effects of CBR1 overexpression on migration and invasion activities because MES-SA cells did not move.

Wound healing assay. Cells were cultured in a six-well plate until they reached confluence. Linear scratch wounds were created in the center of each well with a $1,000-\mu 1$ sterile pipette tip. After $24 \mathrm{~h}$, images were obtained to observe the wounds at the same fields under the microscope, and the separation distance between wound sides was measured as previously reported (36). Each experiment was performed in triplicate, and the mean was obtained from three independent experiments.

Reverse transcription-PCR (RT-PCR). The mRNA expressions of $C D H 1, S N A I L, S L U G, T G F-\beta 1$ and $T G F-\beta 2$ were examined by real-time RT-PCR. Total RNA was isolated with an RNeasy mini kit (cat. no. 74104; Qiagen, Tokyo, Japan). cDNA was synthesized from $1 \mu \mathrm{g}$ of total RNA using a Revertra Ace qPCR RT Master Mix (cat. no. FSQ-201; Toyobo Life Science, Osaka, Japan). RT-PCR was performed using TB 
green Primer Ex Taq II DNA Polymerase (cat. no. RR820S; Takara Bio, Inc., Otsu, Japan) according to the manufacturer's protocol with the following amplifying primer pairs: SNAII (5'-ctccctgtcagatgaggacagt-3' and 5'-tccttgttgcagtatttgcagt-3'), SNAI2 (5'-cctgtcataccacaaccagag-3' and 5'-cttcatcactaatgg ggctttc-3'), CDH1 (5'-cgggaatgcagttgaggatc-3' and 5'-aggatg gtgtaagcgatggc-3'), TGF- $\beta 1$ (5'-tggacaccaactattgcttcag-3' and 5'-gtccaggctccaaatgtagg-3'), TGF- $\beta 2$ (5'-ttgatggcacctccacat atac-3' and 5'-agtggacgtaggcagcaatta-3'), and glyceraldehyde 3-phospate dehydrogenase $(G A P D H)$ (5'-tgcaccaccaactgcttagc-3' and 5'-ggcatggactgtggtcatgag-3'). GAPDH served as an internal control. The thermal cycling conditions were 45 cycles of $95^{\circ} \mathrm{C}$ for $5 \mathrm{sec}$, and $60^{\circ} \mathrm{C}$ for $20 \mathrm{sec}$.

Western blot analysis. Cultured cells were resuspended in RIPA buffer (Wako Pure Chemical Industries, Ltd., Osaka, Japan) and mildly sonicated. The insoluble materials were removed by centrifugation at $15,000 \mathrm{rpm}$ for $10 \mathrm{~min}$ at $4^{\circ} \mathrm{C}$. The supernatant was mixed with SDS sample buffer (New England BioLabs, Tokyo, Japan), and the samples were boiled for $5 \mathrm{~min}$. Ten $\mu \mathrm{g}$ of proteins were electrophoresed on a $10 \%$ SDS-polyacrylamide gel (PAGE). The proteins were then transferred to a polyvinylidene difluoride membrane (New England BioLabs) with a semi-dry type blotting system. The membrane was blocked with blocking solution (5\% skimmed milk with $0.1 \%$ tween 20 dissolved in Tris buffered saline, $\mathrm{pH} 7.5$ ), incubated with the appropriate first antibodies (see below) diluted at 1:1,000 in blocking solution, incubated with the peroxidase-conjugated secondary antibody (see below) diluted at 1:2,000 in blocking solution, incubated in ECL-Western blotting detection regents (GE Healthcare, Little Chalfont, Buckinghamshire, UK) for $5 \mathrm{~min}$ and used to expose the Hyperfilm-ECL (GE Healthcare). The first antibodies were goat anti-human CBR1 polyclonal antibody (ab4148; Abcam, Tokyo, Japan), rabbit anti-human E-cadherin monoclonal antibody (EP700Y; Abcam), mouse anti-human cytokeratin monoclonal antibody (ab668; Abcam), rabbit anti-human $\alpha$-SMA monoclonal antibody (1184-1; Abcam), rabbit anti-human fibronectin polyclonal antibody (ab23750; Abcam), rabbit anti-human N-cadherin polyclonal antibody (ab76057; Abcam), rabbit anti-human vimentin polyclonal antibody (EPR3776; Abcam), rabbit anti-human snail polyclonal antibody (cat. no. 3879; CST, Tokyo, Japan), rabbit anti-human smad 2 monoclonal antibody (cat. no. 3122; CST, Tokyo, Japan), rabbit anti-human Smad 3 monoclonal antibody (cat. no. 9523; CST), rabbit anti-human phospho-Smad 2 monoclonal antibody (cat. no. 3122; CST), rabbit anti-human phospho-Smad 3 monoclonal antibody (cat. no. 3104S; CST), and mouse anti-human $\beta$-tubulin monoclonal antibody (T4026; Sigma-Aldrich Japan K.K.). The second antibodies were anti-rabbit IgG/HRP (PO399), anti-mouse IgG/HRP (PO260), and anti-goat IgG/HRP (PO449; all from Dako; Agilent Technologies Japan, Ltd., Hachioji-shi, Tokyo).

ELISA. After cells were cultured in the medium without FBS for $48 \mathrm{~h}$, TGF- $\beta 1$ concentrations in the cell culture medium were measured by a Quantikine ELISA Human TGF- $\beta 1$ immunoassay kit (cat. no. DB100B; R\&D Systems Inc., Minneapolis, MN, USA), according to the manufacturer's protocols. The absorbance (OD) was measured at $450 \mathrm{~nm}$.
Gelatin zymography. In order to analyze the effect of CBR1 overexpression on the production of activated MMPs, extracellular MMPs in the medium were measured by gelatin zymography as previously reported (17). Cells were cultured at a density of $1 \times 10^{5}$ cells $/ \mathrm{ml}$ in a six-well microtiter plate at $37^{\circ} \mathrm{C}$ for $24 \mathrm{~h}$ under $5 \% \mathrm{CO}_{2}$ in a humidified atmosphere. The medium was replaced with new medium without FBS, and then cells were cultured for another $24 \mathrm{~h}$. After the culture, MMPs were detected with gelatin zymography. Twenty $\mu \mathrm{l}$ of culture medium with $10 \mathrm{ml}$ Red loading buffer (New England Biolabs) without regent buffer was electrophoresed using detector gels containing $0.9 \mathrm{mg} / \mathrm{ml}$ gelatin. As a positive control of MMPs, a standard mixture of pro MMP-9 $(92 \mathrm{kDa})$, pro MMP-2 (72kDa), and MMP-2 (62kDa; Funakoshi, Tokyo, Japan) was electrophoresed on the same gel. The gels were washed for $1 \mathrm{~h}$ in $2.5 \% \mathrm{w} / \mathrm{v}$ aqueous Triton X-100 to remove SDS and renature the activity of MMPs, and then incubated in activation buffer $(50 \mathrm{mM}$ Tris- $\mathrm{HCl}, 200 \mathrm{mM} \mathrm{NaCl}, 5 \mathrm{mM}$ $\mathrm{CaCl}_{2}, \mathrm{pH} 7.5$ ) at $37^{\circ} \mathrm{C}$ for $72 \mathrm{~h}$. The activities of MMPs were detected as transparent gelatinolytic bands by staining with CBB R-250. The band intensities were measured with Image J software. In the experiments with MES-SA cells, we could not see the effects of CBR1 overexpression on MMP secretion because MES-SA cells did not secret MMP due to the character of the cells.

Statistical analysis. Unpaired Student's t-test was used to compare the two groups. To analyze differences between groups, one-way ANOVA followed by Tukey's test was used. $\mathrm{P}<0.05$ was considered to indicate a statistically significant difference. All statistics were analyzed with SPSS 5.0 J for Windows (SAS Institute Inc., Cary, NC, USA).

\section{Results}

Establishment of a clone overexpressing CBRI. To evaluate the roles of CBR1 in malignant behaviors of uLMS cells, clones overexpressing CBR1 were established by transfecting sense cDNA to CBR1 into SKN cells and MES-SA cells (CBR1). Cells that were transfected with empty vector were used as a control (Mock). Western blot analysis confirmed that CBR1 is overexpressed in both CBR1 clones (Fig. 1A). Parent cells and mock cells appeared as spindle-shaped fibroblasts while both types of CBR1 cells appeared as cobble stone-like epithelial cells (Fig. 1B).

Cell proliferation, cell migration, and wound healing assays. After four days of culture, the number of cells was significantly lower in the CBR 1 clones than in the mock clones for both SKN and MES-SA cells (Fig. 2), suggesting that CBR1 overexpression decreased cell proliferation.

The wound healing assay showed that the cells in the CBR1 clone filled the wounded area significantly more slowly than did the cells in the mock clone for both cell types (Fig. 3A). In the migration assay, the number of SKN cells that migrated to the lower side of the membrane was significantly lower in the CBR1 clone than that in the mock clone (Fig. 3B).

MMPs secretions and cell invasion assay. SKN cells were examined in these assays, in which MMP-2 and MMP-9 
A

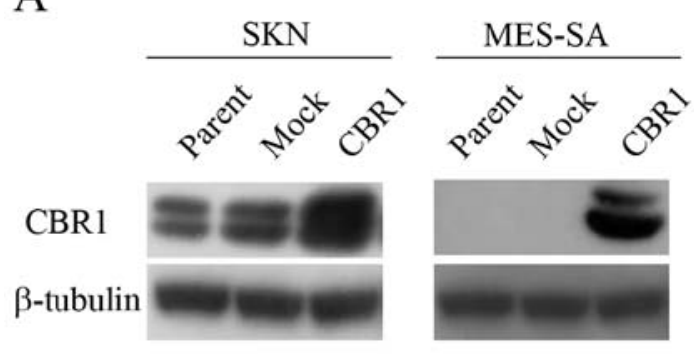

B
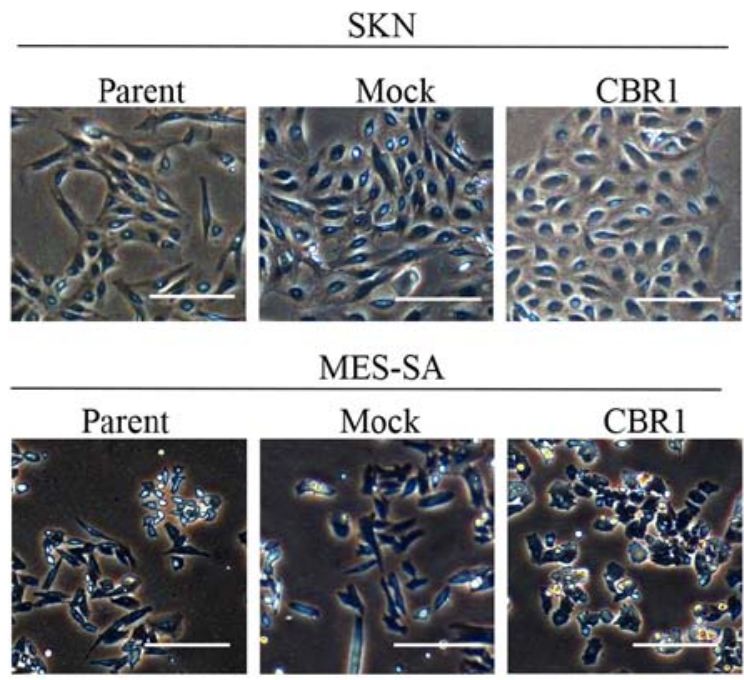

Figure 1. Establishment of clones overexpressing CBR1. cDNA to CBR1 was transfected into a uLMS cell line (SKN) and a uterine sarcoma cell line (MES-SA) (CBR1 clones). A clone that was transfected with empty vector was used as a control (Mock clones). (A) Expression levels of CBR1 were evaluated by western blot analysis. $\beta$-tubulin was used as an internal control. (B) Cell morphologies of parent cells, mock cells, and CBR1 cells in SKN and MES-SA. Scale bar, $200 \mu \mathrm{m}$. CBR1, carbonyl reductase 1; uLMS, uterine leiomyosarcoma.
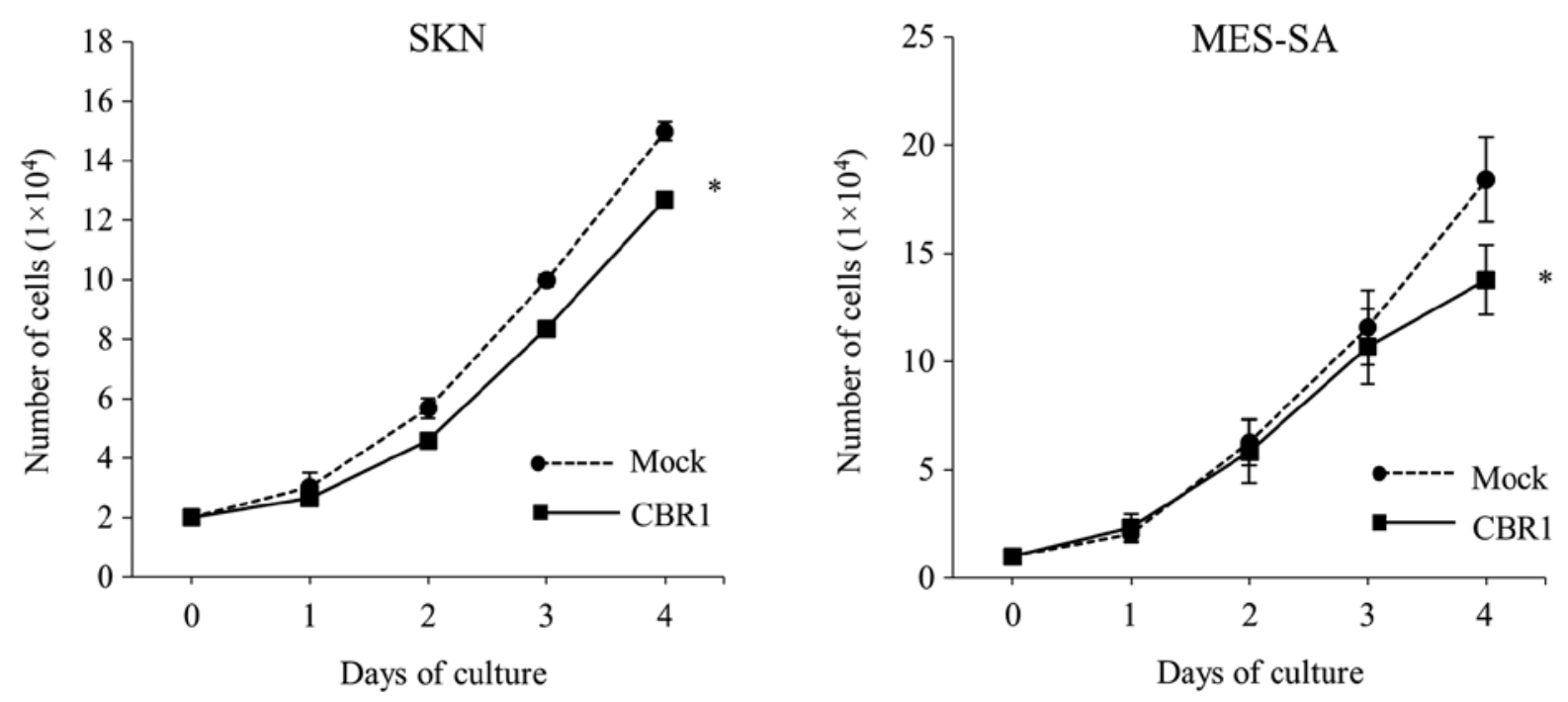

Figure 2. Effect of CBR1 overexpression on cell proliferation in SKN and MES-SA cells. The number of cells in the mock and CBR1 clones was measured at each point. Data are presented as the mean \pm SEM of three independent experiments. ${ }^{*} \mathrm{P}<0.05$ vs. Mock. CBR1, carbonyl reductase 1 .

secretions were determined by gelatin zymography. The band intensities of pro-MMP-9, pro-MMP-2, and MMP-2 were significantly lower in the CBR1 clone than those in the mock clone (Fig. 4A). The CBR1 clone showed significantly lower invasion activities than the mock clone (Fig. 4B).

Effects of CBRI overexpression on EMT-related markers. In SKN cells, the epithelial markers E-cadherin and cytokeratin were expressed more strongly in the CBR1 clone than in the mock clone (Fig. 5A). In MES-SA cells, cytokeratin was also expressed more strongly in the CBR1 clone (Fig. 5A). Since MEA-SA cells do not express E-cadherin, we did not observe the effect of CBR1 overexpression on E-cadherin. On the other hand, in SKN cells, the expression levels of the mesenchymal markers fibronectin and N-cadherin were lower in the CBR1 clone than in the mock clone, while the expression levels of
aSMA and vimentin did not differ between the two clones (Fig. 5A). In MES-SA cells, the expression levels of fibronectin, $\alpha$ SMA, and $\mathrm{N}$-cadherin were lower in the CBR1 clone than in the mock clone (Fig. 5A).

Snail (SNAII) and Slug (SNAI2) are transcription factors that repress E-cadherin expression (30). The protein expression of Snail (Fig. 5A) and the mRNA levels of SNAII and SNAI2 (Fig. 5B) were all significantly lower in the CBR1 clone than in the mock clone in both cell lines. These results suggest that EMT is suppressed in the CBR1 clone overexpressing CBR1.

TGF- $\beta$ production and signaling in CBRl overexpressing clone. We investigated whether CBR1 overexpression affects TGF- $\beta$ s production. TGFB1 and TGFB2 mRNA levels were significantly lower in the CBR1 clone than in the mock clone in both SKN and MES-SA cells (Fig. 6A). The TGF- $\beta 1$ 
A
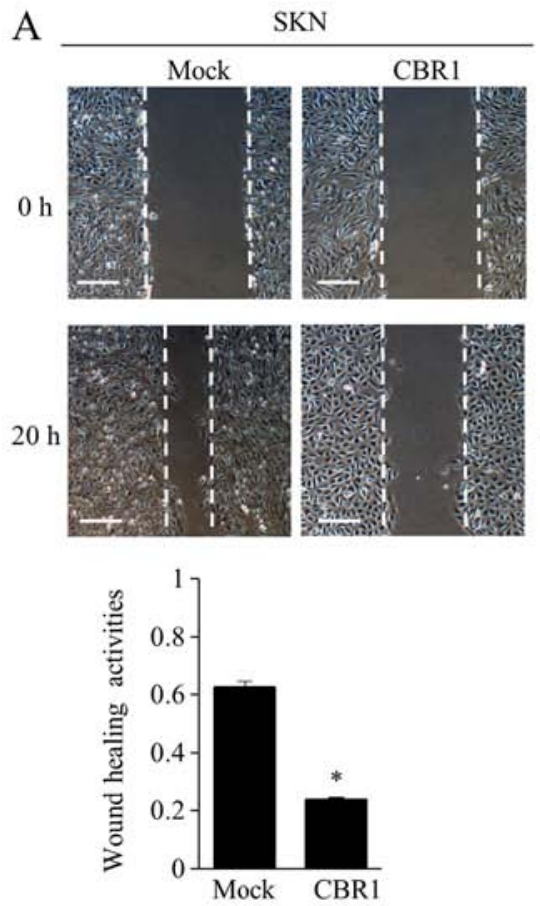
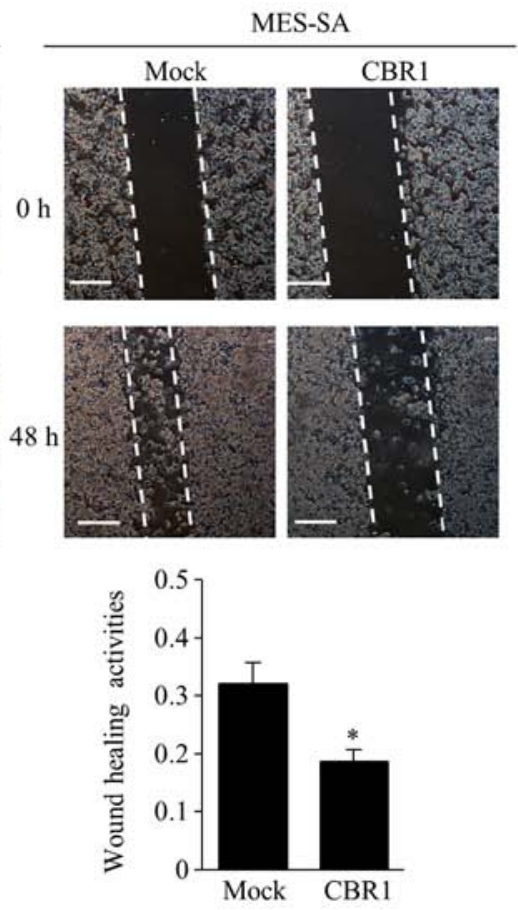

B
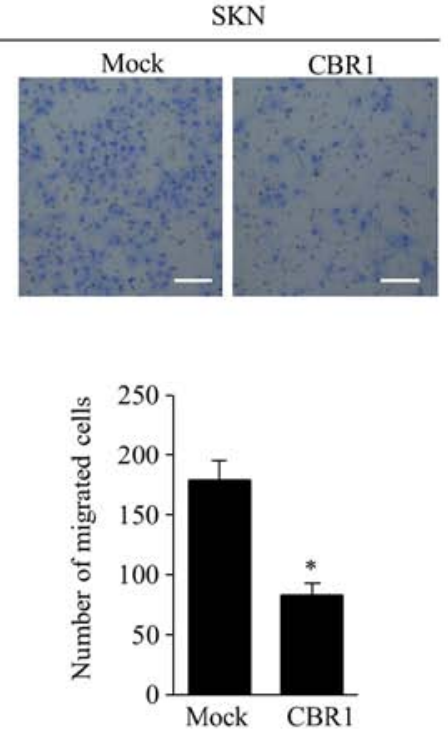

Figure 3. Effects of CBR1 overexpression on migration activities. (A) Wound healing assay in SKN and MES-SA cells. (Top) Representative photos. Vertical lines indicate the wound margins. (Bottom) Migratory activity was calculated by dividing the migration distance by the original width. Scale bar, $200 \mu \mathrm{m}$. Data are presented as the mean \pm SEM of three independent experiments. ${ }^{*} \mathrm{P}<0.05$ vs. Mock. (B) Migration assay in SKN cells. (Top) Representative photos. Scale bar, $200 \mu \mathrm{m}$. (Bottom) The number of the migrated cells was counted in five randomized and the mean was calculated. Magnification, x200. Data are presented as the mean \pm SEM of three independent experiments. ${ }^{*}<<0.05$ vs. Mock. CBR1, carbonyl reductase 1.

A

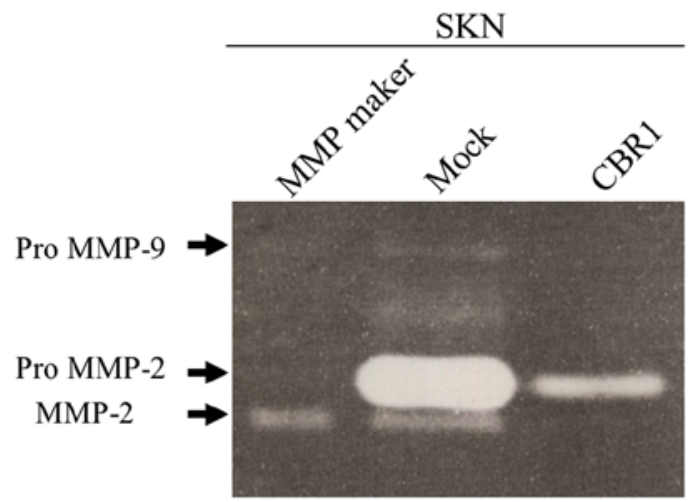

Pro MMP-9

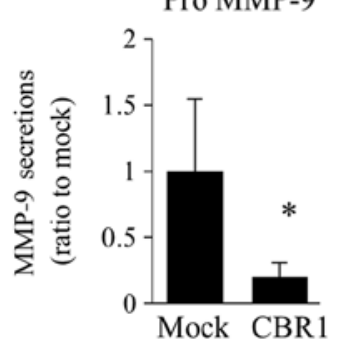

Pro MMP-2

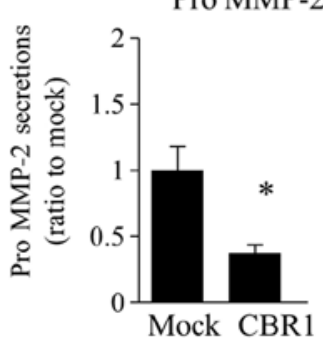

B

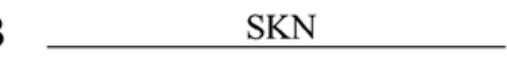

Mock
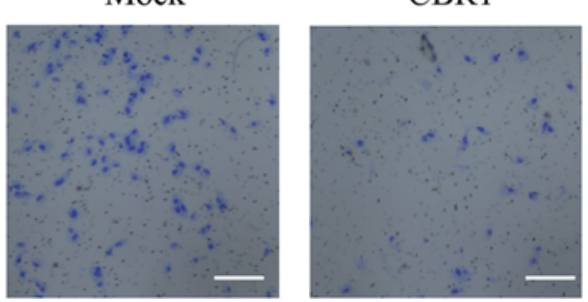

MMP-2
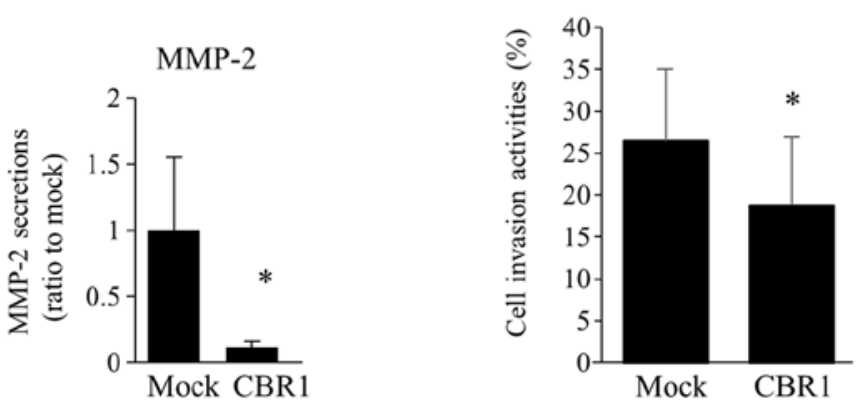

Figure 4. Effects of CBR1 overexpression on MMP secretions and invasion activities in SKN cells. (A) MMP secretions were measured in the cultured medium by gelatin zymography. (Top) A representative photo. (Bottom) The intensities of the bands were measured using ImageJ software. Data are expressed as the ratio to the mock clone and are presented as the mean \pm SEM of three independent experiments. " $\mathrm{P}<0.05$ vs. Mock. (B) Invasion assay. (Top) Representative images. Scale bar, $200 \mu \mathrm{m}$. (Bottom) The ratio of the invaded cells was calculated by dividing the number of the cells in the coated chamber by the number of the invaded cells in the uncoated chamber. Data are presented as the mean \pm SEM of three independent experiments. "P<0.05 vs. Mock. CBR1, carbonyl reductase 1; MMP, matrix metalloproteinase.

concentrations in the medium were also significantly lower in the CBR1 clone than in the mock clone in both cell lines
(Fig. 6B). These results indicate that TGF- $\beta$ s production is suppressed in the CBR1 clone overexpressing CBR1. 

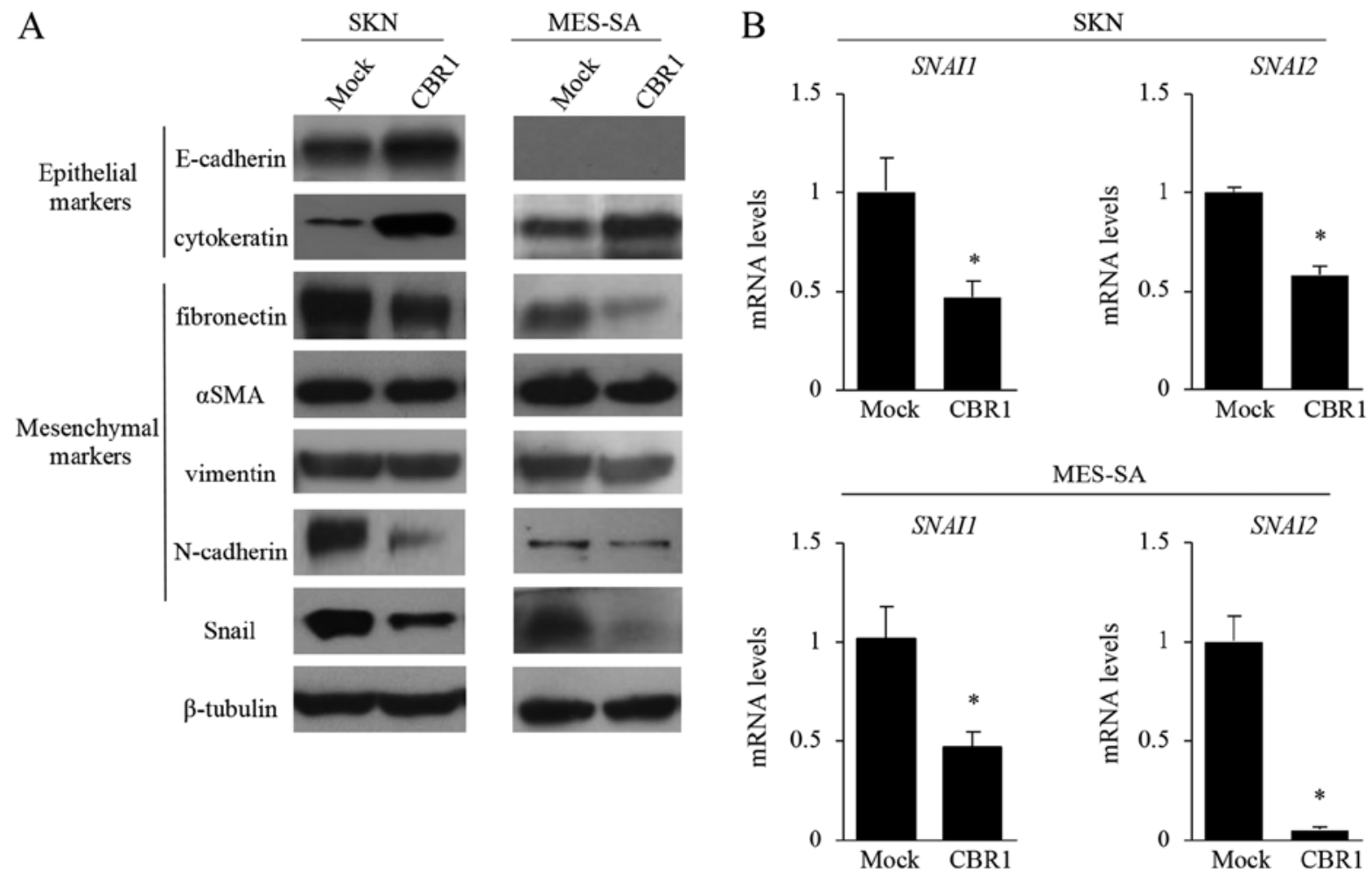

Figure 5. Effects of CBR1 overexpression on the EMT-related markers in SKN and MES-SA cells. (A) Expression levels of epithelial markers (E-cadherin and cytokeratin), mesenchymal markers (fibronectin, $\alpha$ SMA, vimentin and N-cadherin) and Snail were measured by western blot analysis. $\beta$-tubulin was used as an internal control. (B) Reverse transcription-PCR analysis of SNAII and SNAI2 which are transcription factors of EMT. GAPDH was used as an internal control. Data are expressed as the ratio of the mRNA level of each molecule to the GAPDH mRNA level, and are presented as the mean \pm SEM of three independent experiments. "P $<0.05$ vs. Mock. CBR1, carbonyl reductase 1; EMT, epithelial mesenchymal transition; SNAII, snail family transcriptional repressor 1; SNAI2, snail family transcriptional repressor $2 ; \alpha \mathrm{SMA}, \alpha$-smooth muscle actin.

We further investigated whether CBR1 overexpression suppresses TGF $\beta /$ Smad signaling. The expression levels of phosphorylated-Smad2 (P-Smad2) and phosphorylated-Smad3 (P-Smad3) as measured by Western blotting were significantly lower in the CBR1 clone than in the mock clone in both SKN and MES-SA cells (Fig. 6C). This result suggests that the TGF- $\beta$ signaling pathway is suppressed in the CBR1 clone.

TGF- $\beta$ signaling and the EMT. To investigate whether TGF- $\beta$ signaling is associated with the promotion of EMT in uLMS cells, SKN parent cells were treated with a TGF- $\beta$ receptor blocker, SB431542. The expression levels of P-Smad2 and P-Smad 3 proteins were confirmed to be decreased by SB 431542 (Fig. 7A). The protein and mRNA levels of E-cadherin ( $\mathrm{CDHI})$ expression were increased while those of Snail (SNAII) were decreased by SB 431542 treatment (Fig. 7A and B). In addition, SB431542 treatment significantly decreased cell proliferation activities (Fig. 7C), but did not affect cell morphology (data not shown). These results suggest that TGF- $\beta$ signaling is associated with the promotion of EMT.

We further examined whether TGF- $\beta$ stimulation promotes EMT in uLMS cells. Parent cells (control) and CBR1-overexpressing SKN cells were treated with TGF- $\beta 1$. The expression levels of P-Smad 2 and P-Smad 3 were confirmed to be increased by TGF- $\beta$ stimulation in control cells (Fig. 7D). The protein and mRNA levels of E-cadherin $(\mathrm{CDH} 1)$ were decreased while those of Snail (SNAII) were increased by TGF- $\beta$ treatment in control cells (Fig. 7D and E). TGF- $\beta$ treatment did not affect the cell proliferation activity (Fig. 7F) or cell morphology (data not shown). These results provide additional evidence that TGF- $\beta$ signaling is partly associated with the promotion of EMT in uLMS cells.

On the other hand, the effects by TGF- $\beta$ treatment on the CBR1 cells were similar to those observed in the control cells (Fig. S1), indicating that CBR1 overexpression did not affect TGF- $\beta$ signaling stimulated by exogenous TGF- $\beta$. This could be due to either (1) the suppressive effect of CBR1 on TGF- $\beta$ signaling and EMT may have been overcome by exogenous TGF- $\beta$ or (2) CBR1 inhibits endogenous TGF- $\beta$ expression, but does not directly interrupt the TFG- $\beta$ signaling pathway.

\section{Discussion}

The present results show that CBR1 overexpression inhibited cell proliferation, migration, and invasion activities and that these changes were accompanied by increased expressions of epithelial markers (E-cadherin and cytokeratin), and decreased expressions of mesenchymal markers (N-cadherin and fibronectin) in uLMS. These results suggest that the increased CBR1 expression represses malignant behaviors of uLMS cells by inhibiting EMT. We previously reported that increased CBR1 expression repressed migration and invasion activities by inhibiting EMT in uterine cervical and endometrial cancers $(17,18)$. Therefore, it is likely that CBR1 controls malignant behaviors of tumor cells in uLMS as well as in uterine cancers. This the first report suggesting the anti-tumor effect of CBR1 in uLMS. 
A

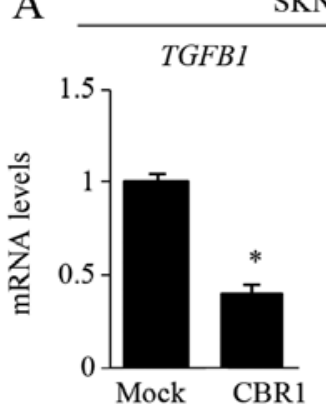

B

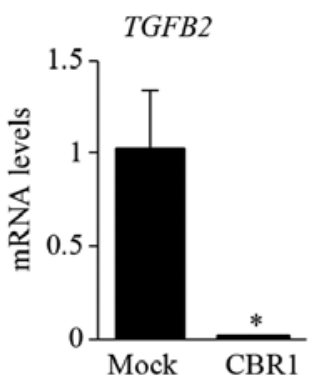

MES-SA
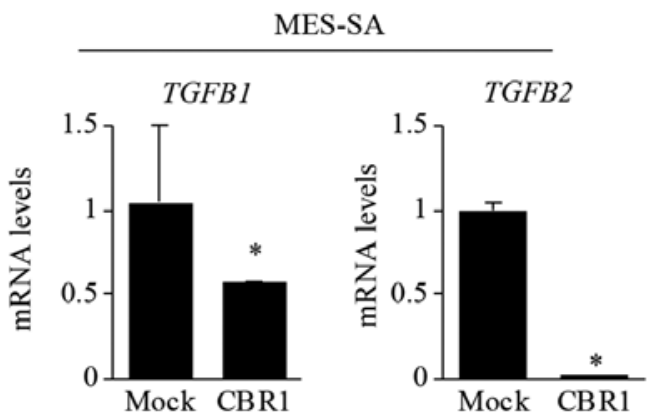

$\mathrm{C}$

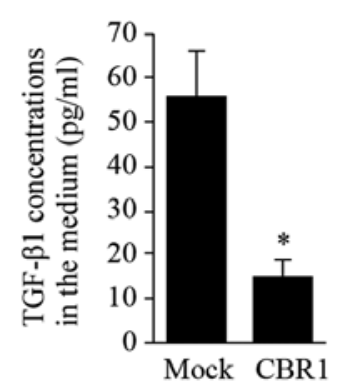

MES-SA

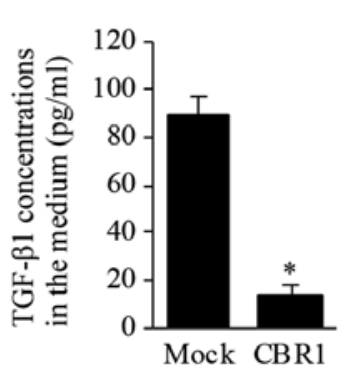

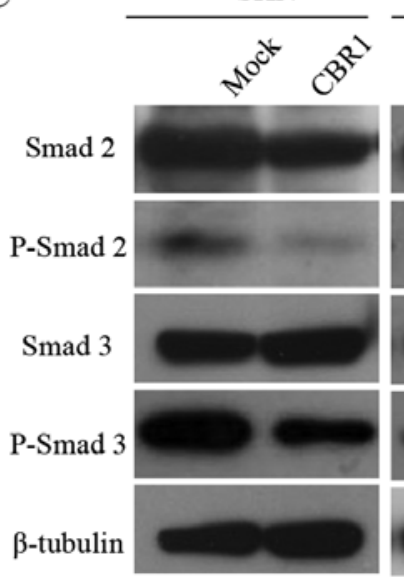

MES-SA

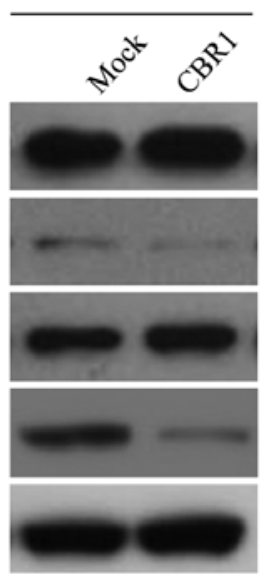

Figure 6. Effects of CBR1 overexpression on production and signaling of TGF- $\beta$ in SKN and MES-SA cells. (A) Reverse transcription-PCR analysis for $T G F-\beta 1$ and $T G F-\beta 2$. GAPDH was used as an internal control. Data are expressed as the ratio of the mRNA level of each molecule to the $G A P D H$ mRNA level, and presented as the mean \pm SEM of three independent experiments. "P $<0.05$ vs. Mock. (B) TGF- $\beta 1$ concentrations in the medium were measured by ELISA. Data are presented as the mean \pm SEM of three independent experiments. "P<0.05 vs. Mock. (C) Expression levels of Smad2, Smad3, p-Smad2 and p-Smad3 were evaluated by western blot analysis. CBR1, carbonyl reductase $1 ; \mathrm{p}$, phosphorylated; TGF- $\beta$, transforming growth factor- $\beta$.

The mechanism by which CBR1 inhibits EMT in uLMS cells remains unclear. Our previous microarray and IPA pathway analyses showed that suppression of CBR1 expression activates the intracellular signaling pathway of TGF- $\beta$ in uterine cervical cancer (21). TGF- $\beta$ is a multifunctional cytokine, and has been shown to be a modulator of EMT in many types of cancers $(24,34,39-44)$. However, it is still controversial how TGF- $\beta$ acts on sarcomas. Qi et al $(35,45)$ reported that the TGF- $\beta / \mathrm{Smad} /$ Snail signaling pathway is closely associated with EMT, which promotes cell proliferation, migration, and invasion in synovial sarcomas. Dwivedi et al (46) showed that TGF- $\beta$ promotes cell migration by phosphorylating Smad 2 and Smad 3 in uterine carcinosarcomas. These findings suggest that TGF- $\beta$ signaling is associated with EMT in certain sarcomas as well as in cancers. Our results clearly show that TGF- $\beta$ treatment activates EMT, that the blockage of TGF- $\beta$ signaling inhibits EMT in uLMS cells (Fig. 7), and that CBR1 overexpression inhibits TGF- $\beta$ production and signaling (Fig. 6). Therefore, these results suggest that CBR1 inhibits EMT through suppressing TGF- $\beta$ production and the subsequent signaling pathway in uLMS cells. This is also the first report showing that that the suppressive effect of CBR1 is mediated through TGF- $\beta$ signaling.

In this study, the blockage of TGF- $\beta$ signaling by SB 431542 (a TGF- $\beta$ type 1 receptor-selective blocker) decreased cell proliferation activities while exogenous TGF- $\beta$ treatment had no effects. TGF- $\beta$ is a multifunctional cytokine and exogenous treatment of TGF- $\beta$ stimulates several intracellular signaling pathways (47). Therefore, the effect of a TGF- $\beta$ receptor blocker may more correctly reflect the involvement of TGF- $\beta$ signaling pathway. It is unclear why the exogenous TGF- $\beta$ treatment and TGF- $\beta$-blocker did not influence cell morphology. We speculate that the experimental conditions used in this study changed the levels of EMT markers, but did not affect cellular phenotypes such as cell morphology. The findings that exogenous TGF- $\beta$ treatment had no effects on cell proliferation and that TGF- $\beta$-blocker did not influence cell morphology do not contradict our hypothesis that TGF- $\beta$ signaling is involved in the suppressive effect of CBR1 on EMT. Since CBR1 is involved in a number of intracellular signaling pathways other than TGF- $\beta$ signaling pathways (21), CBR1 may regulate cell proliferation activities or cell morphology through several intracellular signaling pathways.

Much is known about the role of EMT in epithelial malignant tumors (cancers) whereas little is known about its role in mesenchymal malignant tumors. Since sarcomas originally have mesenchymal features, they do not need to undergo EMT. However, there is accumulating evidence that EMT is involved in malignant behaviors in a variety of mesenchymal malignant tumors $(28,30-33,48)$. Yang et al $(48)$ reported that suppression of EMT with an increase in E-cadherin expression was associated with inhibition of cell proliferation and invasion activities in leiomyosarcomas, which is consistent with our results. EMT enhances mesenchymal activities and promotes malignant behaviors such as cell proliferation and invasion activities in mesenchymal malignant tumor cells $(27,30,49-53)$, which may be associated with aggressive clinical features. Therefore, controlling EMT may be a key to controlling the aggressive malignant behaviors of sarcomas. Interestingly, the reverse process of EMT, termed the mesenchymal to epithelial transition (MET), has been reported to occur in sarcomas, which results in more favorable tumor behaviors $(27,49,54,55)$. Our 
A

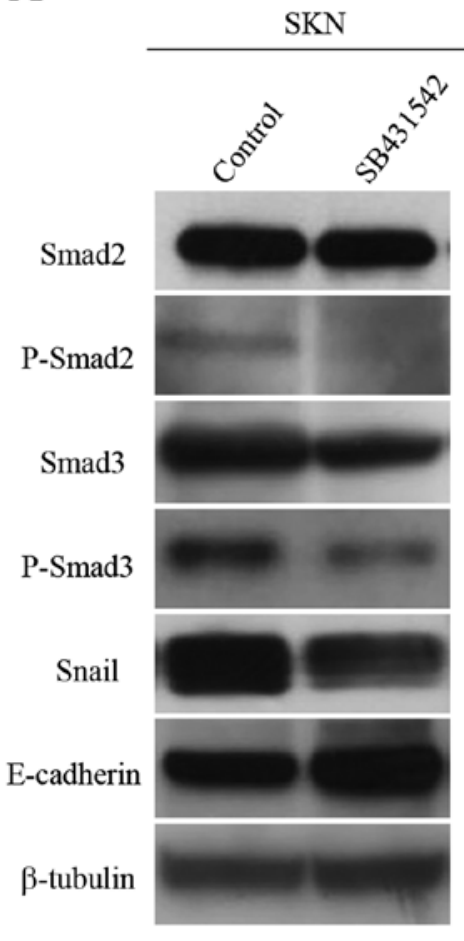

$\mathrm{D}$
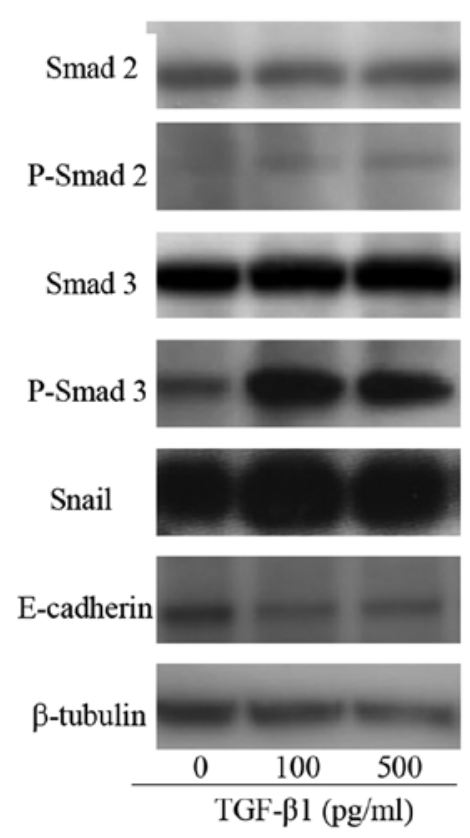

B

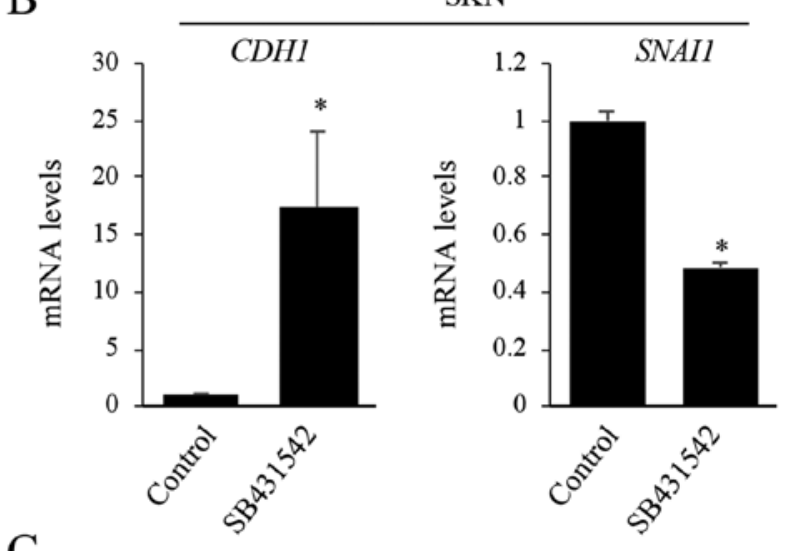

$\mathrm{C}$

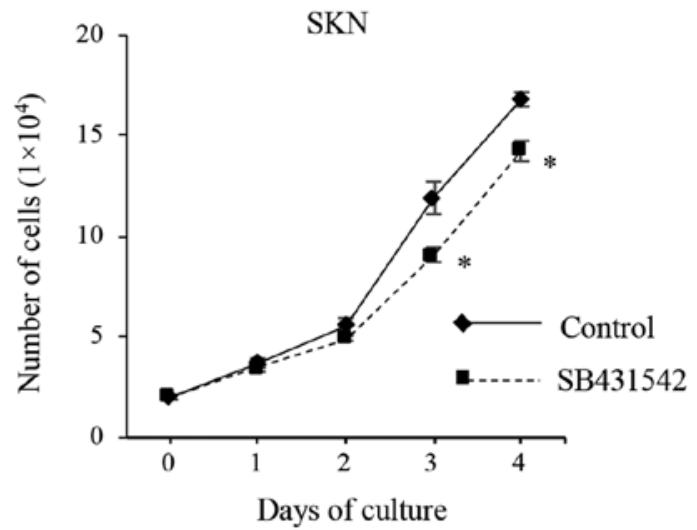

$\mathrm{E}$

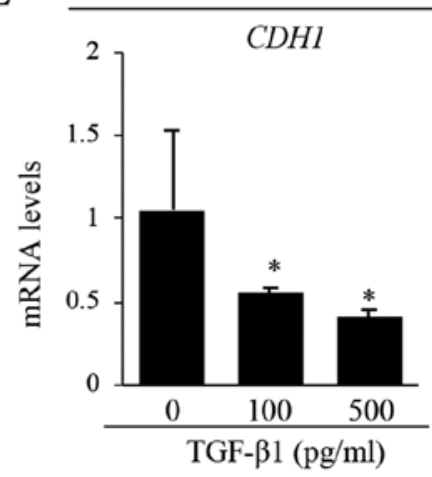

Control

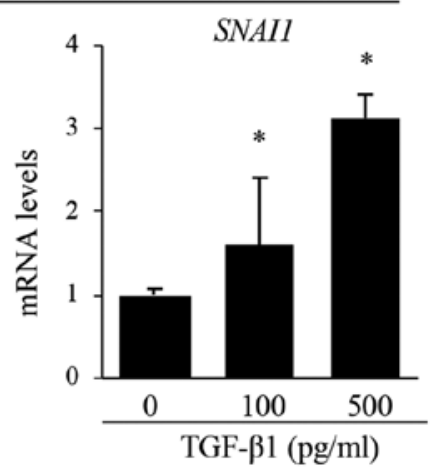

$\mathrm{F}$

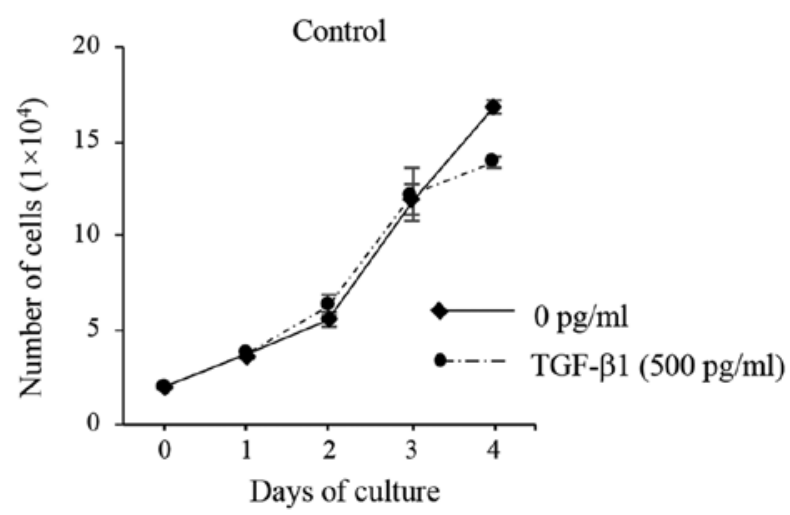

Figure 7. Effects of TGF- $\beta$ and a TGF- $\beta$ blocker on EMT. (A and B) SKN parent cells were treated with SB431542 (TGF- $\beta$ type 1 receptor-selective blocker). (C) SKN parent cells (Control) were treated with SB431542 for 4 days. " $\mathrm{P}<0.05$ vs. control. (D and E) SKN parent cells (Control) were treated with recombinant TGF- $\beta 1(0,100$ and $500 \mathrm{pg} / \mathrm{ml})$ for $24 \mathrm{~h}$. ${ }^{*} \mathrm{P}<0.05 \mathrm{vs} .0 \mathrm{pg} / \mathrm{ml}$. The expression levels of p-Smad2, p-Smad3, Snail and E-cadherin were evaluated by western blot analysis. $\beta$-Tubulin was used as an internal control. mRNA levels of $C D H 1$ and SNAII were measured by reverse transcription-PCR. GAPDH was used as an internal control. Data are presented as the ratio of the mRNA level of each molecule to the GAPDH mRNA level. (F) SKN parent cells (Control) were treated with SB431542 or recombinant TGF- $\beta 1(500 \mathrm{pg} / \mathrm{ml})$ for 4 days. The number of cells was measured at each point. Data are presented as the mean \pm SEM of three independent experiments. $T G F-\beta$, transforming growth factor- $\beta$; EMT, epithelial mesenchymal transition; p, phosphorylated; $C D H 1$, cadherin $1 ; S N A I 1$, snail family transcriptional repressor 1 . 
results show that CBR1 inhibits EMT. In other words, CBR1 may induce MET in uLMS cells.

It is unclear how CBR1 suppresses TGF- $\beta$ expression. Miura et al (22) reported that CBR1 represses c-jun expression in ovarian cancer cells. c-jun combines with AP-1, and the complex stimulates TGF- $\beta$-induced EMT and prevents apoptosis (56). Therefore, there is a possibility that CBR1 inhibits TGF- $\beta$ expression and its subsequent signaling by decreasing $\mathrm{c}$-jun expression. However, further studies are needed to test these ideas.

In this study, only one cell line (SKN) derived from uLMS cells was used because we were unable to find other uLMS cell lines that are commercially available. This is a limitation of this study although the data using a uterine sarcoma cell line (MEA-SA) were very similar to those observed in SKN cells.

In summary, the present study shows that increased CBR1 expression inhibits malignant behaviors and EMT by suppressing TGF- $\beta$ signaling in uLMS cells. uLMS is a highly malignant mesenchymal tumor, and there is no efficient therapy for it except surgery at present. Our findings suggest that CBR1 can be a promising new target for therapy of uLMS. A therapeutic shifting of uLMSs to a more epithelial-like status could attenuate their aggressive features and improve patient prognosis.

\section{Acknowledgements}

Not applicable.

\section{Funding}

The present study was supported in part by JSPS KAKENHI (grant nos. 23592425, 23791845, 26462525, 15K10719 and $16 \mathrm{H} 07009)$ for Scientific Research from the Ministry of Education, Science and Culture, Japan.

\section{Availability of data and materials}

The datasets used during the present study are available from the corresponding author on reasonable request.

\section{Authors' contributions}

TK and NS designed the study. TK, AM, MO, KN and KS performed the experiments. TK and SS analyzed and interpreted the data. TK drafted the first manuscript. NS directed the research and drafted the final manuscript. All authors read and approved the final manuscript.

\section{Ethics approval and consent to participate}

Not applicable.

\section{Patient consent for publication}

Not applicable.

\section{Competing interests}

The authors declare that they have no competing interests.

\section{References}

1. Zang Y, Gu L, Zhang Y, Wang Y and Xue F: Identification of key genes and pathways in uterine leiomyosarcoma through bioinformatics analysis. Oncol Lett 15: 9361-9368, 2018.

2. Ricci S, Stone RL and Fader AN: Uterine leiomyosarcoma: Epidemiology, contemporary treatment strategies and the impact of uterine morcellation. Gynecol Oncol 145: 208-216, 2017.

3. George S, Barysauskas C, Serrano C, Oduyebo T, Rauh-Hain JA, Del Carmen MG, Demetri GD and Muto MG: Retrospective cohort study evaluating the impact of intraperitoneal morcellation on outcomes of localized uterine leiomyosarcoma. Cancer 120: 3154-3158, 2014

4. Raine-Bennett T, Tucker LY, Zaritsky E, Littell RD, Palen T, Neugebauer R, Axtell A, Schultze PM, Kronbach DW, Embry-Schubert J, et al: Occult uterine sarcoma and leiomyosarcoma: Incidence of and survival associated with morcellation. Obstet Gynecol 127: 29-39, 2016.

5. Einstein MH, Barakat RR, Chi DS, Sonoda Y, Alektiar KM, Hensley ML and Abu-Rustum NR: Management of uterine malignancy found incidentally after supracervical hysterectomy or uterine morcellation for presumed benign disease. Int J Gynecol Cancer 18: 1065-1070, 2008.

6. Oduyebo T, Rauh-Hain AJ, Meserve EE, Seidman MA, Hinchcliff E, George S, Quade B, Nucci MR, Del Carmen MG and Muto MG: The value of re-exploration in patients with inadvertently morcellated uterine sarcoma. Gynecol Oncol 132: 360-365, 2014.

7. Parker WH, Fu YS and Berek JS: Uterine sarcoma in patients operated on for presumed leiomyoma and rapidly growing leiomyoma. Obstet Gynecol 83: 414-418, 1994.

8. Harris JA, Swenson CW, Uppal S, Kamdar N, Mahnert N, As-Sanie S and Morgan DM: Practice patterns and postoperative complications before and after US Food and Drug Administration safety communication on power morcellation. Am J Obstet Gynecol 214: e1-98.e13, 2016.

9. Ducie JA and Leitao MM Jr: The role of adjuvant therapy in uterine leiomyosarcoma. Expert Rev Anticancer Ther 16: 45-55, 2016.

10. Amant F, Lorusso D, Mustea A, Duffaud F and Pautier P: Management strategies in advanced uterine leiomyosarcoma: Focus on trabectedin. Sarcoma 2015: 704124, 2015.

11. Kapp DS, Shin JY and Chan JK: Prognostic factors and survival in 1396 patients with uterine leiomyosarcomas: Emphasis on impact of lymphadenectomy and oophorectomy. Cancer 112: 820-830, 2008

12. Zivanovic O, Leitao MM, Iasonos A, Jacks LM, Zhou Q, Abu-Rustum NR, Soslow RA, Juretzka MM, Chi DS, Barakat RR, et al: Stage-specific outcomes of patients with uterine leiomyosarcoma: A comparison of the international Federation of gynecology and obstetrics and American joint committee on cancer staging systems. J Clin Oncol 27: 2066-2072, 2009.

13. Penning TM and Drury JE: Human aldo-keto reductases: Function, gene regulation, and single nucleotide polymorphisms. Arch Biochem Biophys 464: 241-250, 2007.

14. Mindnich RD and Penning TM: Aldo-keto reductase (AKR) superfamily: Genomics and annotation. Hum Genomics 3: 362-370, 2009.

15. Wermuth B, Bohren KM, Heinemann G, von Wartburg JP and Gabbay KH: Human carbonyl reductase. Nucleotide sequence analysis of a cDNA and amino acid sequence of the encoded protein. J Biol Chem 263: 16185-16188, 1988.

16. Ismail E, Al-Mulla F, Tsuchida S, Suto K, Motley P, Harrison PR and Birnie GD: Carbonyl reductase: A novel metastasis-modulating function. Cancer Res 60: 1173-1176, 2000.

17. Murakami A, Fukushima C, Yoshidomi K, Sueoka K, Nawata S, Yokoyama Y, Tsuchida S, Ismail E, Al-Mulla F and Sugino N: Suppression of carbonyl reductase expression enhances malignant behaviour in uterine cervical squamous cell carcinoma: Carbonyl reductase predicts prognosis and lymph node metastasis. Cancer Lett 311: 77-84, 2011.

18. Murakami A, Yakabe K, Yoshidomi K, Sueoka K, Nawata S, Yokoyama Y, Tsuchida S, Al-Mulla F and Sugino N: Decreased carbonyl reductase 1 expression promotes malignant behaviours by induction of epithelial mesenchymal transition and its clinical significance. Cancer Lett 323: 69-76, 2012.

19. Osawa Y, Yokoyama Y, Shigeto T, Futagami M and Mizunuma H: Decreased expression of carbonyl reductase 1 promotes ovarian cancer growth and proliferation. Int J Oncol 46: 1252-1258, 2015. 
20. Umemoto M, Yokoyama Y, Sato S, Tsuchida S, Al-Mulla F and Saito Y: Carbonyl reductase as a significant predictor of survival and lymph node metastasis in epithelial ovarian cancer. $\mathrm{Br}$ J Cancer 85: 1032-1036, 2001.

21. Nishimoto Y, Murakami A, Sato S, Kajimura T, Nakashima K, Yakabe K, Sueoka K and Sugino N: Decreased carbonyl reductase 1 expression promotes tumor growth via epithelial mesenchymal transition in uterine cervical squamous cell carcinomas. Reprod Med Biol 17: 173-181, 2018

22. Miura R, Yokoyama Y, Shigeto T, Futagami M and Mizunuma $\mathrm{H}$ : Inhibitory effect of carbonyl reductase 1 on ovarian cancer growth via tumor necrosis factor receptor signaling. Int J Oncol 47: $2173-2180,2015$

23. Thiery JP, Acloque H, Huang RY and Nieto MA: Epithelialmesenchymal transitions in development and disease. Cell 139: 871-890, 2009

24. Lamouille S, Xu J and Derynck R: Molecular mechanisms of epithelial-mesenchymal transition. Nat Rev Mol Cell Biol 15 178-196, 2014

25. Perl AK, Wilgenbus P, Dahl U, Semb H and Christofori G: A causal role for E-cadherin in the transition from adenoma to carcinoma. Nature 392: 190-193, 1998.

26. Banyard $\mathrm{J}$ and Bielenberg DR: The role of EMT and MET in cancer dissemination. Connect Tissue Res 56: 403-413, 2015.

27. Kahlert UD, Joseph JV and Kruyt FAE: EMT- and MET-related processes in nonepithelial tumors: Importance for disease progression, prognosis, and therapeutic opportunities. Mol Oncol 11: 860-877, 2017.

28. Song C, Liu W and Li J: USP17 is upregulated in osteosarcoma and promotes cell proliferation, metastasis, and epithelial-mesenchymal transition through stabilizing SMAD4. Tumour Biol 39: 1010428317717138, 2017.

29. Zeng SX, Cai QC, Guo CH, Zhi LQ, Dai X, Zhang DF and Ma W: High expression of TRIM29 (ATDC) contributes to poor prognosis and tumor metastasis by inducing epithelial-mesenchymal transition in osteosarcoma. Oncol Rep 38: 1645-1654, 2017.

30. Sannino G, Marchetto A, Kirchner T and Grünewald TGP Epithelial-to-Mesenchymal and Mesenchymal-to-Epithelial transition in mesenchymal tumors: A paradox in sarcomas? Cancer Res 77: 4556-4561, 2017.

31. Kong G, Jiang Y, Sun X, Cao Z, Zhang G, Zhao Z,Zhao Y, Yu Q and Cheng G: Irisin reverses the IL-6 induced epithelial-mesenchymal transition in osteosarcoma cell migration and invasion through the STAT3/Snail signaling pathway. Oncol Rep 38: 2647-2656, 2017.

32. Peng C, Zhao H, Song Y, Chen W, Wang X, Liu X, Zhang C, Zhao J Li J, Cheng G, et al: SHCBP1 promotes synovial sarcoma cell metastasis via targeting TGF- $31 /$ Smad signaling pathway and is associated with poor prognosis. J Exp Clin Cancer Res 36: 141, 2017.

33. Tang J, Shen L, Yang Q and Zhang C: Overexpression of metadherin mediates metastasis of osteosarcoma by regulating epithelial-mesenchymal transition. Cell Prolif 47: 427-434, 2014

34. Zavadil J and Böttinger EP: TGF-beta and epithelial-to-mesenchymal transitions. Oncogene 24: 5764-5774, 2005.

35. Qi Y, Wang N, He Y, Zhang J, Zou H, Zhang W, Gu W, Huang Y, Lian $\mathrm{X}, \mathrm{Hu} \mathrm{J}$, et al: Transforming growth factor- $\beta 1$ signaling promotes epithelial-mesenchymal transition-like phenomena, cell motility, and cell invasion in synovial sarcoma cells. PLoS One 12: e0182680, 2017.

36. Yoshidomi K, Murakami A, Yakabe K, Sueoka K, Nawata S and Sugino N: Heat shock protein 70 is involved in malignant behaviors and chemosensitivities to cisplatin in cervical squamous cell carcinoma cells. J Obstet Gynaecol Res 40: 1188-1196, 2014.

37. Murakami A, Nakagawa T, Kaneko M, Nawata S, Takeda O, Kato $\mathrm{H}$ and Sugino N: Suppression of SCC antigen promotes cancer cell invasion and migration through the decrease in E-cadherin expression. Int J Oncol 29: 1231-1235, 2006.

38. Nakagawa T, Murakami A, Torii M, Nawata S, Takeda O and Sugino N: E-cadherin increases squamous cell carcinoma antigen expression through phosphatidylinositol-3 kinase-Akt pathway in squamous cell carcinoma cell lines. Oncol Rep 18: 175-179, 2007.
39. Xu J, Lamouille S and Derynck R: TGF-beta-induced epithelial to mesenchymal transition. Cell Res 19: 156-172, 2009.

40. Deckers M, van Dinther M, Buijs J, Que I, Löwik C, van der Pluijm G and ten Dijke P: The tumor suppressor Smad4 is required for transforming growth factor beta-induced epithelial to mesenchymal transition and bone metastasis of breast cancer cells. Cancer Res 66: 2202-2209, 2006.

41. Morizane R, Fujii S, Monkawa T, Hiratsuka K, Yamaguchi S, Homma $\mathrm{K}$ and Itoh $\mathrm{H}$ : miR-34c attenuates epithelial-mesenchymal transition and kidney fibrosis with ureteral obstruction. Sci Rep 4: 4578, 2014.

42. Valcourt U, Kowanetz M, Niimi H, Heldin CH and Moustakas A TGF-beta and the Smad signaling pathway support transcriptomic reprogramming during epithelial-mesenchymal cell transition. Mol Biol Cell 16: 1987-2002, 2005.

43. Ghahhari NM and Babashah S: Interplay between microRNAs and $\mathrm{WNT} / \beta$-catenin signalling pathway regulates epithelial-mesenchymal transition in cancer. Eur J Cancer 51: $1638-1649,2015$

44. Liu QQ, Chen K, Ye Q, Jiang XH and Sun YW: Oridonin inhibits pancreatic cancer cell migration and epithelial-mesenchymal transition by suppressing Wnt/ $\beta$-catenin signaling pathway. Cancer Cell Int 16: 57, 2016.

45. Qi Y, Wang CC, He YL, Zou H, Liu CX, Pang LJ, Hu JM, Jiang JF, Zhang WJ and Li F: The correlation between morphology and the expression of TGF- $\beta$ signaling pathway proteins and epithelial-mesenchymal transition-related proteins in synovial sarcomas. Int J Clin Exp Pathol 6: 2787-2799, 2013.

46. Dwivedi SK, McMeekin SD, Slaughter K and Bhattacharya R: Role of TGF- $\beta$ signaling in uterine carcinosarcoma. Oncotarget 6 : 14646-14655, 2015.

47. Horbelt D, Denkis A and Knaus P: A portrait of transforming growth factor $\beta$ superfamily signalling: Background matters. Int J Biochem Cell Biol 44: 469-474, 2012.

48. Yang J, Eddy JA, Pan Y, Hategan A, Tabus I, Wang Y, Cogdell D, Price ND, Pollock RE, Lazar AJ, et al: Integrated proteomics and genomics analysis reveals a novel mesenchymal to epithelial reverting transition in leiomyosarcoma through regulation of slug. Mol Cell Proteomics 11: 2405-2413, 2010.

49. Li Y, Shao G, Zhang M, Zhu F, Zhao B, He C and Zhang Z: miR-124 represses the mesenchymal features and suppresses metastasis in Ewing sarcoma. Oncotarget 8: 10274-10286, 2017.

50. Zhang M, Wang D, Zhu T and Yin R: RASSF4 overexpression inhibits the proliferation, invasion, EMT, and Wnt signaling pathway in osteosarcoma cells. Oncol Res 25: 83-91, 2017.

51. Zhang D, Jiang F, Wang X and Li G: Downregulation of Ubiquitin-Specific protease 22 inhibits proliferation, invasion, and Epithelial-mesenchymal transition in osteosarcoma cells. Oncol Res 25: 743-751, 2017.

52. Guo X, Zhang J,Pang J,He S, Li G, Chong Y,Li C, Jiao Z,Zhang S and Shao M: MicroRNA-503 represses epithelial-mesenchymal transition and inhibits metastasis of osteosarcoma by targeting c-myb. Tumour Biol 37: 9181-9187, 2016.

53. Zhang D, Wang S, Chen J, Liu H, Lu J, Jiang H, Huang A and Chen Y: Fibulin-4 promotes osteosarcoma invasion and metastasis by inducing epithelial to mesenchymal transition via the PI3K/Akt/mTOR pathway. Int J Oncol 50: 1513-1530, 2017.

54. Somarelli JA, Shetler S, Jolly MK, Wang X, Bartholf Dewitt S, Hish AJ, Gilja S, Eward WC, Ware KE, Levine $\mathrm{H}$, et al: Mesenchymal-epithelial transition in sarcomas is controlled by the combinatorial expression of MicroRNA 200s and GRHL2. Mol Cell Biol 36: 2503-2513, 2016.

55. Yang J, Du X, Wang G, Sun Y, Chen K, Zhu X, Lazar AJ, Hunt KK, Pollock RE and Zhang W: Mesenchymal to epithelial transition in sarcomas. Eur J Cancer 50: 593-601, 2014.

56. Yi EY, Park SY, Jung SY, Jang WJ and Kim Y: Mitochondrial dysfunction induces EMT through the TGF- $\beta /$ Smad/Snail signaling pathway in Hep3B hepatocellular carcinoma cells. Int J Oncol 47: 1845-1853, 2015. 